\title{
VALENTIM FERNANDES E JACOBO CROMBERGER: OS PIONEIROS NA BIOGRAFIA DO DIREITO DE AUTOR PORTUGUÊS E O INÍCIO DO DIREITO DA LITERATURA EM LÍNGUA PORTUGUESA
}

\author{
VICTOR GAMEIRO DRUMMOND ${ }^{1}$
}

\begin{abstract}
RESUmo: O texto apresenta, descritiva e criticamente, as análises referentes às primeiras atribuições de privilégios ocorridas no século XVI, em Portugal, bem como suas reflexões na história do Direito de Autor em Portugal e, por consequência, nos países que, historicamente, com ele se relacionam, considerando que tais atribuições constituem o marco inicial do direito da literatura em língua portuguesa.
\end{abstract}

PalaVRas-ChaVE: direito de autor; privilégios; direito da literatura; história do direito de autor.

\section{O SURGIMENTO DO DIREITO DE AUTOR E DE UM DIREITO DA LITERATURA}

No âmbito do amplo universo inerente ao direito e à literatura, há três modos de se compreender a intersecção temática entre essas duas áreas do conhecimento: o direito como literatura; o direito na literatura e o direito da literatura.

O campo do direito como literatura pretende analisar os aspectos do direito que se relacionam com a análise das ferramentas linguísticas, estruturais, observando a posição do direito como literatura e, de alguma forma, a própria linguagem utilizada na criação jurídica.

\footnotetext{
1 Pós-doutor em Direito pela Faculdade de Direito da Universidade de Lisboa (FDUL). Doutor em Direito pela Universidade Estácio de Sá (UNESA). Mestre em Direito pela Faculdade de Direito da Universidade de Lisboa (FDUL). Professor do PPGD do Centro Universitário de Guanambi. Presidente do Instituto Latino de Direito e Cultura (ILDC). Presidente do Comitê Jurídico e de Desenvolvimento da Federação de Entidades de Gestão Coletiva do Audiovisual - Latin Artis. Advogado no Rio de Janeiro, Brasil. CV Lattes: http://lattes.cnpq.br/4862618570634510. E-mail: victor@victordrummond.com
} 
O direito na literatura dedica-se a examinar as circunstâncias, as temáticas, as apreciações sobre o direito que fazem parte da literatura, compreendo a relação entre o que a criação literária pode trazer ao universo de compreensão do Direito. O Direito, dessa forma, por assim dizer, apareceria dentro da literatura.

O terceiro ambiente de análise da interseção temática entre essas duas áreas de conhecimento seria o direito da literatura, o que compreende a apreciação do direito na proteção do processo de criação literária, no que se configura histórica e sistematicamente como parte do direito de autor.

Num olhar particularmente iniciado sob o ponto de vista do direito e da literatura, esse terceiro ambiente relacional pode ser inicialmente considerado o menos relevante.

No tocante, porém, à apreciação do direito que possibilita a proteção do processo de criação, o direito de autor é área do direito de grande relevo e destaque, que contém inúmeros institutos autônomos.

Nesse sentido, a análise dos primeiros passos do que se configuraria historicamente como direito de autor é relevante para o direito e literatura, especialmente no que se refere ao direito da literatura, até porque o direito de autor e os próprios privilégios de impressão começaram por atribuir proteção às obras literárias e musicais (mais precisamente, partituras, nesse caso), em detrimento de obras de qualquer outra natureza, iniciando todas as discussões inerentes ao direito de autor desde então.

O presente texto tem como objetivo a análise, na sua fonte original, dos primeiros três privilégios de impressão atribuídos em língua portuguesa, vislumbrando a hipótese de se compreender, na origem, os primeiros movimentos do direito de autor e de uma proteção do direito da literatura. O tema é particularmente interessante porque se pode concluir que, quando da outorga dos primeiros privilégios, houve a proteção dos investimentos dos impressores em detrimento da atribuição de benefícios para proteção dos autores.

Nesse sentido, deve-se ter em conta que o direito de autor não nasce, romanticamente, como sistema protetivo dos autores, dos criadores que foram somente sendo "romantizados" ao longo da história. Muito pelo contrário, os criadores, ao menos no âmbito das artes, foram durante muitíssimo tempo considerados marginais, e, como marginais, não 
importava que fossem titulares de direitos, conceito que, diga-se de passagem, até o século XVIII, não existia como tal no cenário das criações artísticas. O mesmo se referia, obviamente, aos autores de obras literárias que, como marginais (numa acepção literal da expressão), não possuíam grande consideração social. Por outro lado, ainda que o direito de autor tenha primordialmente albergado a ideia de proteção da criatividade artística, os intelectuais, tão autores quanto os criadores do ambiente artístico, sequer participaram do primeiro momento das proteções históricas do direito de autor. Daí a relevância de se compreender esse embrião do direito de autor como o início de proteção dos autores a partir de uma proteção da literatura, que era e a atividade vinculada à ideia de possibilidade de reprodução de obras criativas.

Paradoxalmente, e em linhas gerais, portanto, nos primeiros movimentos autorais, os autores não davam as cartas. Isso se observa em muitos países, entre os quais, França, Inglaterra, Itália e Portugal, entre outros. O investimento em equipamento técnico foi, assim, o que conduziu ao estabelecimento de exclusividades protetivas do próprio investimento, antes de caracterizar a proteção de um sujeito do processo criativo.

No caso de Portugal, essa lógica também se repete, como vinha ocorrendo com os impressores, tipógrafos e livreiros nos idos do século XV, que, aliás, foi o momento do surgimento efetivo dos privilégios de impressão em território europeu em geral, especialmente como consequência da diáspora germânica de impressores da região da Mogúncia.

O que se pretende com este estudo é apontar a pré-existência do direito de autor como tal, ao analisar os primeiros privilégios atribuídos, em Portugal, com o objetivo de garantir exclusividade ao que foi sendo então denominada "a nobre arte da impressão". Como consequência, fixar os primórdios de um direito da literatura, relacionado a um fundamento basilar de sua projeção como arte e vinculado a um aspecto de ordem tecnológica, qual seja, o surgimento da imprensa, que, por sua vez, irá possibilitar o desenvolvimento da literatura escrita como forma de expressão artística. 
Para isso, são analisados três dos primeiros privilégios de impressão da história de Portugal e, como decorrência histórica, em língua portuguesa. Sempre lembrando que o surgimento da imprensa foi o estopim tecnológico que permitiu a existência de todo esse complexo de discussões, ainda que a valorização (e compreensão) do sujeito a partir da modernidade tenha sido, entre outros elementos, um aspecto de ordem não tecnológica que conduziu ao surgimento do debate sobre o direito aos criadores.

Os primeiros privilégios apresentam o testemunho de que os primeiros passos na direção do direito de autor em Portugal, como também em outros países europeus, foram dados na direção da proteção dos investidores e não dos sujeitos-criadores, e de que a literatura e a possibilidade de reprodução das obras literárias ambientavam a principal celeuma na ocasião.

\section{OS PRIVILÉGIOS: ANTECEDENTES HISTÓRICOS DO DIREITO DE AUTOR E DO DIREITO DA LITERATURA}

Como é de largo conhecimento da doutrina e já faz parte do senso comum autoralista, os antecedentes das leis de direito de autor eram os denominados privilégios, algumas vezes nomeados como privilégios de impressão. No caso das monarquias europeias, tratavam-se do que se denominam em língua espanhola como privilégios graciosos, instituídos por simples vontade, benevolência ou parcialidade do superior que o atribuía (Rogel; Drummond, 2010, p. 1)².

A essa indicação, porém, é importante somar algumas outras ideias para a compreensão dos privilégios e sua importância no direito de autor e no desenvolvimento da literatura e do direito à ela relacionado.

Havia muitos tipos de privilégios e, de fato, é um pouco reducionista tentar tratar deles no âmbito demasiadamente genérico do direito de autor, como se um único momento histórico ou circunstância os fizessem surgir.

\footnotetext{
2 Conforme Rogel e Drummond (2010), no caso de Portugal, atribui-se a Valentim Fernandes o primeiro privilégio de impressão para o livro de histórias de Marco Paulo (também nomeado Marco Pólo) de autoria de Nicolau Vêneto. Há, porém, divergência de data, prevalecendo a atribuição de que tal fato teria ocorrido no ano de 1502 . Pereira (2008, p. 52) e Leitão (2011, p. 23) estão entre os que indicam que o primeiro privilégio teria sido atribuído em 1502, para que Valentim Fernandes pudesse publicar a sua tradução de Marco Paulo. No caso da Espanha, os privilégios concedidos aos impressores datam inicialmente da época dos Reis Católicos (1502) e os atribuídos aos autores, do reinado de Carlos III (1753).
} 
A bem da verdade, os privilégios eram uma forma de instituir poderes (e somente incipientemente direitos) bem anterior ao advento do constitucionalismo (portanto, são obviamente anteriores ao advento do conceito de constitucionalismo e da "igualdade" revolucionária) e também anteriores à codificação napoleônica. Não havia, assim, a universalização exigida aos direitos que, posteriormente, seria salientada e compreendida como uma condição de possibilidade para se estar diante de um direito, efetivamente.

Logo, quando se trata de analisar historicamente os privilégios de impressão não há como se falar, nesse sentido, de modo algum, em igualdade de condições de atribuições de direito a autores (sujeitoscriadores), ou mesmo em sua comparação com editores ou quaisquer outros agentes atuantes, no que seria ainda o embrionário início de uma "produção cultural".

Ou seja, ao se tratar de compreender a ideia de privilégios (desde o medievo), há de se apontar seu sentido numa ordem do que esses significavam, observando-se de um modo genérico, e não somente como atribuições que conduziam à possibilidade de exclusividades para a impressão.

E é exatamente nessa ordem de ideias que Hespanha vai indicar que "abaixo do plano do reino, proliferavam as ordens jurídicas particulares [...] todas elas protegidas pela regra da preferência do particular sobre o geral. A designação comum para estas ordens jurídicas era a de privilégio” (2012, p. 158). Tratavam-se, pois, de atribuições de direito que circulavam no âmbito do direito comum, que, afinal e sendo bem reducionista, era um direito romano reinterpretado. No mais, além do direito comum, o direito canônico também possuía acentuada presença na sociedade medieval, além de direitos outros, dos que viviam fora do universo territorial cristão.

Por outro lado, há uma concepção evidenciada do que são os privilégios pelo status recebido pelos privilegiados, atribuindo-se a esses sujeitos condições diferenciadas na sociedade. Era o caso, somente para exemplificar de modo muito genérico, de parte da nobreza espanhola que possuía imunidade tributária; a quem também não era possível castigar com penas infamantes e que eram impedidos de serem presos por dívidas (a não ser devidas ao reino). Também lhes era permitido cumprir penas em 
casa, e mantinham a casa e o cavalo como não sujeitos a embargos (Escudero, 2012, p. 675).

O conceito de privilégios como concessões de vantagens expressas e que desempenhavam importante papel na Baixa Idade Média (Gilissen, 2013, p. 292) deve ser entendido como um elemento de fortalecimento da compreensão do que eles significavam na ordem jurídica e do respeito que lhes era atribuído como elemento que inspirava respeito social, ainda que se possa questionar sua condição de lei, visto que não possuíam suas características principais, quais sejam: generalidade e permanência (Gilissen, 203, p. 293).

Há, porém, uma importante característica que deve ser observada no entendimento dos privilégios e de seu desenvolvimento histórico como elemento formador do Direito. Havia muitos que eram atribuídos baseados no costume e, portanto, eram uma simples "continuação" de práticas costumeiras e de atribuições anteriormente atribuídas. Essa característica muitas vezes demonstrava a força dos privilégios e deve ser compreendida no desenvolvimento histórico do direito de autor pela sua importância como força motriz da própria categoria jurídica que viria, pois, a surgir do conteúdo dos privilégios de impressão, seja protegendo os investidores, nos seus primeiros passos, seja atribuindo direitos aos sujeitos-criadores.

Vale indicar as palavras de Gilissen (2013, p. 292), ao tratar dos privilégios (genericamente e não exclusivamente os de impressão) como práticas costumeiras:

Na maior parte dos casos, estes privilégios não fazem outra coisa senão confirmar uma situação já existente, fundada no costume: o grupo privilegiado está já em posse de vantagens reconhecidas de facto: a carta de concessão apenas confirma esta situação (2013, p. 292, grifamos) ${ }^{3}$.

Ora, essa compreensão mais aberta e ampla sobre os privilégios, indica a diferença entre o que poderia constituir uma ideia de privilégios de modo genérico e o que eram, especificamente, os privilégios de impressão. Ao mesmo tempo, porém, uma interpretação dessa natureza também

3 A figura dos privilégios como atribuição de condição privada e fonte de Direito pode ser observada já no Digesto, por exemplo em Paulus, Modestinus e Isidoro como indica Garcia-Gallo (1971, p.111). 
amplia a compreensão dos privilégios para muito além de (somente) meras atribuições reais.

Isso se evidencia pelo fato de que os privilégios eram muitos mais do que simples atribuições reais, ainda que no caso dos privilégios de impressão eles fossem geralmente uma consequência da atribuição de condições de exclusividades pelo poder real. Nesse sentido, havia exclusividades, pois, de diversas naturezas. Enquanto alguns privilégios eram atribuídos para que o beneficiário recebesse genericamente as mesmas vantagens de figuras pertencentes à nobreza, como o privilégio atribuído aos impressores Jacobo Cromberger (1508) e Germão Galhardo (15304, entre outros, havia privilégios exclusivamente voltados ao tema da impressão, como os atribuídos a Valentim Fernandes em 1502 e em 1503. Como se conclui, portanto, no âmbito da biografia do direito de autor e do direito da literatura, pode-se apontar diferenças de conteúdo também nos privilégios genericamente nomeados de "privilégios de impressão". A existência de diferenças entre os privilégios acima mencionados demonstra essa informação, que, por sua vez, poderá ser comprovada no decorrer deste estudo.

Ou seja, até mesmo no pequeno universo dos denominados privilégios de impressão, há divergência de sentido entre o que esses acabam por significar como documentos, ou seja, no concernente à sua natureza, e também, como consequência, o que significam historicamente, sobretudo na biografia do direito de autor.

Indo mais além, e voltando ao conceito ainda mais amplo dos privilégios, o que se pode concluir é que a ideia de privilégio é bastante mais extensa do que a que costumeiramente se faz referência na literatura de direito de autor.

É importante, pois, salientar essas breves diferenciações, compreendendo-se que privilégios também eram (1) os estatutos (das cidades); (2) o costume instituído e praticado nos burgos e, por fim, (3) os

4 Galhardo, ainda que tenha sido um importante impressor do século XV, em Portugal, não tem seus privilégios analisados neste estudo, visto que a ideia aqui desenvolvida é tratar dos primeiríssimos documentos que atribuem exclusividades para impressões naquela país e, nesse sentido, Fernandes e Cromberger são os pioneiros, tendo sido agraciados com os três primeiros privilégios da história portuguesa. 
direitos especiais de pessoas ou de grupos particulares5. Somam-se, pois, a esses os privilégios reais e/ou instituídos pelos monarcas de um modo geral, nos quais efetivamente se vai encontrar as atribuições que levaram à denominação de privilégios de impressão, sendo esses uma espécie do gênero privilégios reais.

Deve ser reiterada tal diferenciação também no que se refere aos privilégios genéricos e aos privilégios de impressão. Isso porque percebe-se um equívoco nessa terminologia ao ser empregada genericamente quando se conclui que muitos dos primeiros privilégios de impressão foram, em verdade, destinados a atividades genéricas, como é o caso do privilégio atribuído, em Portugal, a alguns dos impressores pioneiros, como Cromberger.

Há uma obviedade na constatação de que não se tratava muitas vezes, portanto, da atribuição de privilégios especificamente determinados para a permissão de impressão, mas de conteúdos muito mais amplos, por meio de alvarás para que os referidos impressores beneficiários viessem a usufruir de condições idênticas a dos cavaleiros da casa real, o que, como indicado, ocorreu com Jacob Cromberger, como também bem destaca Deslandes:

Jacob Cromberger era allemão e impressor de livros. Foi
convidado a servir em Portugal, onde requereu e alcançou
a 20 de fevereiro do anno de 1508 a mercê de todas as
graças, privilegios, liberdades e honras que então haviam
os cavalleiros da real casa. O alvará da mercê concede a
mesma distincção a todos quantos então exerciam ou de
futuro viessem a exercer nobre arte da typographia
(Deslandes, 1881, p. 7).

Ora, a determinação era muito mais ampla do que somente relacionada à impressão de obras em geral e, também, obviamente muito mais ampla se comparada com os privilégios atribuídos para impressão para textos específicos, o que havia ocorrido antes, por exemplo, naquele país, com Valentim Fernandes, na qualidade de impressor (em 1502, $1503 \mathrm{e}$ em outras ocasiões) e viria a ocorrer com Gonçalo de Baena (1536), Balthasar Dias (1537) e com Luiz de Camões (1572), sendo certo que, no caso destes últimos três, na qualidade de autores de obras literárias ${ }^{6}$, portanto, de modo sensivelmente diferente ao atribuído aos privilégios

\footnotetext{
5 Dos quais se extrai uma semântica propriamente acentuada de privilégio no sentido de vantagem pessoal.

6 Com exceção de Baena, cuja obra possuía natureza literária e também musical.
} 
objeto deste estudo da fase preliminar dos privilégios. Haveria aqui, podese dizer, uma distinção importante na compreensão de um direito da literatura, pois, enquanto os pioneiros das atribuições de privilégios eram investidores, os sujeitos-criadores aparecem em cena como beneficiados somente pouco mais de 30 anos depois.

Por outro lado, cabe reafirmar que a atribuição de privilégios e condição idêntica a dos cavaleiros era vista como grande honra aos impressores que possuíam alta consideração social e é importante destacar o seu relevo.

Em primeiro lugar, deve ser indicado que, de fato, há uma certa obviedade, até mesmo como raciocínio histórico, em compreender que os privilégios de impressão decorreriam de uma atribuição real, ao se interpretar (e essa é uma das interpretações para a expressão) os privilégios genericamente compreendidos como antecedentes ao surgimento das leis de direito de autor e como atribuições oriundas de atribuições monárquicas.

Por outro lado, e não como oposição a essa ideia, deve ser compreendido que, se a ordem jurídica se acentuava numa diferenciação de status pessoal e de fato essa era uma característica bastante presente no antigo regime, não seria absolutamente incompreensível que as primeiras leis de direito de autor tivessem como destinatários aqueles que foram seus antecedentes (como sujeitos) na atribuição de privilégios. Assim como não seria incompreensível que fosse admitido e aceitável socialmente sua atribuição em decorrência de uma compreensão de que os privilégios possuíam validade como normas jurídicas (generalizando, para que caibam todas as noções de privilégio indicadas).

Como corretamente indica Hespanha (2012, p. 159): “os direitos de cada um eram a tradução jurídica da situação de que cada um gozava naquela sociedade hierarquizada”. E havia alguns que alcançavam tamanha posição de destaque que conseguiam atribuições de privilégios além de seu próprio território, o que era o caso de Cromberger, que estava sediado no território espanhol e não, no português.

Dessa forma, ausente o componente da ideia de igualdade e aceita, consequentemente, a ideia de diferenciação de status pessoal e de que o privilégio representava uma espécie de ordem jurídica particular, não seria absurdo compreender o surgimento de privilégios que fossem atribuídos a 
grupos determinados. Nesse sentido, a atribuição de privilégios que determinavam condições assemelhadas às dos cavaleiros reais demonstra a importância da tipografia, dos impressores e daquela que foi denominada como a "nobre arte da impressão", do que se conclui que era atividade bastante considerada pelas monarquias, de um modo geral.

Somando a condição que conduziria à atribuição de privilégios por um status social diferenciado à consideração social sobre a nobre arte da impressão, o status diferenciado também poderia ser atribuído a um beneficiário que mereceria consideração pela sua superioridade social, os quais, como historicamente se foi verificando, eram os editores, os impressores, os tipógrafos. Ou seja, a superioridade e a consideração social elevada eram atribuídas ao tipógrafo e ao impressor e não ao autor, que ainda vinha se formando como sujeito realmente autônomo de direito e, principalmente, como merecedor de consideração social. Esse é, portanto, um importante elemento que indica, inclusive, um surgimento filosoficamente deficitário do direito de autor. Só não haveria de se julgar filosoficamente deficitário se a tipografia fosse considerada tecnicamente mais relevante do que a própria criação. Qual o problema que se apresenta, porém? É que a tipografia, de fato, nos seus primórdios, compreendia em algum sentido uma realização artística na criação das primeiras obras impressas. E essa ideia pode desfazer a noção inicial de que as primeiras impressões eram meras atividades técnicas e não artísticas. Para tal, devese pensar nos incunábulos7 e, no caso de Portugal, pode-se também evocar a existência de obras importantíssimas que eram consideradas, numa expressão contemporânea, "verdadeiras obras de arte", como a Vita Christi. Essa temática, porém, deve ser tratada em outro estudo.

Resta compreender, por fim e para este estudo, que a expressão privilégios possui as diversas acepções apresentadas, sendo relevante, a partir dessa compreensão, analisar os primeiros privilégios atribuídos em Portugal e seus reflexos no amadurecimento dos primeiros passos do direito de autor.

Incunábulo, entre outros significados, designa as impressões ocorridas desde o início da imprensa até o ano de 1500. 


\section{O LIVRO DE NICOLAU VÊNETO SOBRE AS VIAGENS DE MARCO PAULO E O PRIVILÉGIO DE 1502 ATRIBUÍDO A VALENTIM FERNANDES}

O impressor Valentim Fernandes ("Valentim Fernandes, o alemão" ou "Valentim Fernandes de Morávia") foi o primeiro beneficiário de privilégios relacionado à indústria da impressão e da tipografia em Portugal. Fernandes possuía origem alemã, nasceu na Morávia, no século XV, em data imprecisa (na cidade de Olmütz, atualmente Olomouc, na República Tcheca, de onde seguiu para Nürnberg), e faleceu, em data também não precisa (entre 1518 e 1519), em Lisboa, onde seguiu uma tradição de tipógrafos originários da Mogúncia (Mainz). Foi um dos participantes da diáspora dos tipógrafos germânicos após o advento da imprensa, em meados do século XV, naquela região da Europa.

Em seu primeiro momento na Península Ibérica, atuou como "língua" - expressão que se utilizava na época para designar intérprete - do médico germânico de Nürnberg, Jerônimo Münzer (cujo sobrenome, aportuguesado foi Monetário), e consta que daí teria sucessivamente alcançado bons contatos e prestígio com a sociedade local, tendo viajado pela península já dominando o castelhano.

Se é bem verdade que, assim como em outros países europeus, a atribuição de privilégio sob a forma de exclusividade garantia e, de certo modo, ampliava o interesse e a possibilidade de investir na indústria da imprensa local, também deve se compreender que, antes mesmo de ser beneficiado por qualquer privilégio, Fernandes começou atuando como impressor e livreiro. E sua atuação era repetida por outros pioneiros que, antes mesmo de receberem privilégios, investiam na nova indústria. Ou seja, os primeiros impressores e livreiros vinham já atuando no ofício antes mesmo de qualquer exclusividade lhes ser atribuída, e não se pode apontar, portanto, que o advento de privilégios exclusivos, antecessores do contemporâneo direito de autor, seriam a motivação do desenvolvimento da imprensa no primeiro momento. Obviamente, porém, e como se pode imaginar, uma vez garantida a exclusividade, o investimento passa a ser mais seguro e desenvolve a indústria, mas não foram nenhum privilégio ou direito as molas propulsoras das primeiras impressões em Portugal. 
Antes porém da atribuição de qualquer privilégio, como já indicado, Valentim Fernandes já vinha atuando como impressor e também como livreiro, tendo publicado no ano de 1495, em parceria com Nicolau de Saxónia, o texto Vita Christi, de autoria de Ludolfo de Saxônia, considerado o primeiro livro ilustrado impresso em Portugal e umas das obras mais importantes impressas em língua portuguesa. Publicou também o Regimento proveitoso contra a pertenença (sem data conhecida); Votivale missarum secundum ritum Romane curiae (10/04/1496) e a Estoria de muy nobre Vespesiano emperador de Roma (20/04/1496).

Por outro lado, e ainda que haja fontes que indiquem que o primeiro privilégio de impressão tenha sido o que autorizou com exclusividade a Fernandes a imprimir a sua tradução das viagens de Marco Paulo, até pela sua indicação no corpo do texto, há quem duvide da atribuição do privilégio. É o entendimento, por exemplo, de Deslandes:

\begin{abstract}
Apontàmos brevemente algumas noticias que d'elle nos chegaram; são as que seguem: [...] ter traduzido do latim e do toscano em linguagem portugueza a celebre viagem de Marco Paulo aos paizes mais oríentaes no XIII século, bem conhecida dos doutos; o tratado do dominicano Pepino de Bolonha; uma carta da índia do genovez Santo Estevão; e as viagens de Nicolau Conti, escriptas por Poggio, florentino, secretario do papa Eugénio IV; traducção que deu na impressão em Lisboa no anno de 1502, dedicada a el-rei D. Manuel, prestando valioso serviço á litteratura portugueza e á historia dos nossos descobrimento; ter tido a 12 de fevereiro de 1503 o privilegio da impressão dos livros dos Regimentos (1881, p. 31).
\end{abstract}

Em linhas gerais, porém, e a toda a evidência, o livro de histórias de Marco Paulo é considerado o primeiro texto a ser publicado em língua portuguesa sob a autorização de um privilégio real. A indicação do privilégio vai impressa na folha de rosto, como seria comum a partir de então. Posteriormente, em algumas ocasiões, o próprio texto que concedia o privilégio era reproduzido na obra (como é o caso das edições de Os Lusíadas de Camões, de 1572) e, em outras, havia a mera indicação de sua existência, como é o caso do livro de Marco Paulo. Era também comum que os privilégios viessem indicados por meio de um documento oficial assinado pelo rei, por meio de cartazes, documento que não faz parte, porém, do acervo das instituições portuguesas que guardam os documentos históricos que recontam a biografia do direito de autor. 
Por outro lado, há suficientes indícios documentais históricos que alimentam o pioneirismo dos privilégios ser mesmo da obra editada por Fernandes, em 1502, narrando as aventuras de Marco Paulo, especialmente a menção expressa da existência do privilégio na própria obra original após a informação do texto da obra e antes mesmo da epístola e da introdução, segue a indicação do que seria a obra e o privilégio:

Ho livro de Nycolao veneto. Ho trallado da carta de hũu genovês das ditas terras.

Cõ privilegio del Rey nosso senhor. đ̃ nenhuũ faça a jmpressam deste livro. nẽ ho venda em todollos se regnos e senhorios sem liçẽça Valentim fernãdez so pena cõteuda na carta do seu previlegio (Portugal, 1502, p. 1).

Assim como em outros países, esse privilégio inaugura a condição de permissionário ou de outorgado àquele que poderia fazer com que as obras chegassem ao público por meio da multiplicação de exemplares e pela sua reprodução, que, no caso em apreço, foi o impressor e livreiro Valentim Fernandes, e não um autor. A dupla função de impressor e livreiro decorre do fato de que, nas próprias oficinas em que se imprimiam os exemplares, eles poderiam ser vendidos ao público em geral.

Como também acabou por tornar-se uma circunstância historicamente repetida, o privilégio de impressão foi atribuído a um investidor do setor da tipografia em detrimento de uma permissão exclusiva de impressão para qualquer autor. No caso dos privilégios em língua portuguesa, os primeiros atribuídos a autores foram aqueles outorgados a Gonçalo de Baena e Balthasar Dias, respectivamente nos anos de 1536 e 1537, portanto e como já indicado, pouco mais de 30 anos após a atribuição a Fernandes.

Valentim Fernandes foi, assim, um pioneiro na tipografia em Portugal e figura exponencial do surgimento do direito de autor em sua fase ainda mais tenra, tendo recebido várias vantagens em decorrência de suas atividades e reiteradas autorizações para imprimir. Dentre essas, a que lhe foi atribuída no ano seguinte ao primeiro privilégio, datado de 1502, e que lhe garantiu o fornecimento de importante livro para o Reino, o Regimentos dos Juízes e Oficiais em Portugal, cujo privilégio se passa também a analisar. 


\section{O REGIMENTOS DOS JUÍZES E OFICIAIS EM PORTUGAL E O PRIVILÉGIO DE 1503 ATRIBUÍDO A VALENTIM FERNANDES}

Fernandes, pois, reitera-se, já vinha atuando com a tipografia antes de receber o privilégio para a impressão do livro com as histórias de Marco Paulo, inclusive com a impressão de incunábulos, e seguidamente foi beneficiado com o privilégio de impressão pelo rei Dom Manuel I para que pudesse editar e comercializar o livro do Regimento dos Juízes e Oficiais, no ano de 1503.

A autorização, ao que parece, não foi um ato de ofício, tendo havido provocação do impressor para alcançá-la, pois Valentim Fernandes efetuou requerimento ao Comendador Brás A. Correia para que pudesse ocorrer a concessão de privilégio.

É como também interpreta os fatos inerentes à concessão do privilégio, Deslandes, que compilou, ainda na data de 1881, os principais documentos históricos referentes às autorizações diversas e atribuições de privilégio no início da tipografia e das impressões em Portugal:

Teve e gozou [...] Valentim Fernandes [...] o privilégio da impressão dos livros dos Regimentos por alvará de 12 de fevereiro de 1503 que a seu requerimento foi apregoado pelos officiaes das justiças e a todos notificados pelos editaes afixados nos logares mais publicos das cidades (Delandes, 1881, p.13).

Controvérsias a parte sobre qual seria o primeiro privilégio documentalmente concedido, o privilégio datado de 1503 apresenta algumas curiosidades que, desde já, podem ser extraídas do alvará que lhe foi atribuído.

Em primeiro lugar, a qualificação apresentada por Valentim Fernandes para que recebesse o privilégio foi a de livreiro, e não a de impressor: "pareceo Vallentim Fernandez livreiro e apresentou ao dito Comendador este alvará do dito senhor que tall he como se segue" (Portugal, 1502, p.01, grifamos).

Em segundo lugar, o texto parece indicar que os livros para os quais o privilégio estava sendo atribuído encontravam-se já impressos e prontos para a comercialização antes da atribuição:

Nos el Rey per este noso alvará nos praz, pello trabalho que vallentym fernandez tem levado na empresam dos livros dos Regymentos que ora mandamos fazer pera todo o Reyno dos Juizes e oficiaes, que nenh ua pesoa em 
nosos Reynos os nom posa impremir (Portugal, 1502, p. 1 , grifamos).

Esse argumento é também defendido por João José Alves Dias (1995, p. 24), ao apontar que "nessa data já Valentim Fernandes teria, com probabilidade, entregue os livros aos serviços competentes (para a impressão)". Isso porque, como corretamente aduz Dias, "não se faz pregão público e não se afixam 'editais' proibindo a edição por outrem de uma obra que ainda não existe, nem se anuncia que se vai imprimir uma obra ficando por isso todos proibidos de a fazerem" (1995, p. 4), como consequência desse fato. Curioso notar que a existência de livros impressos poderia conduzir à criação de um fato consumado por parte do impressor que como consequência de alguma boa relação com a monarquia, bem como compreendido o entendimento de que os privilégios eram também, como já foi exposto, ordens jurídicas particulares - prepara um ambiente para que Fernandes se antecipasse à atribuição de um privilégio. $\mathrm{Na}$ contemporaneidade, seria acreditar em um direito e exercê-lo antes mesmo de que seja considerado e atribuído.

Ora, não obstante ser Valentim Fernandes uma figura que abarcava a condição e o ofício de impressor e livreiro, além de suas outras atividades não diretamente relacionadas com tais ofícios, mas sempre consideradas de caráter acentuadamente cultas, o fato de que o privilégio fosse atribuído a um livreiro (ou a alguém que ostentasse, entre outras, a condição de livreiro) é de suma importância no início do desenvolvimento do direito de autor e, por conseguinte, do direito da literatura.

Isso ocorre porque, ainda que existisse na época uma acentuada promiscuidade entre o proprietário de todo o material da indústria de tipografia, o impressor, o editor e o livreiro (que seriam hoje as empresas gráficas, as editoras e as livrarias), a atuação e a função estariam relativamente delimitadas. Enquanto o impressor parecia ser o sujeito que buscava as obras para que pudessem efetivamente ser transformadas em produtos, os livreiros atuavam como comerciantes que, ao fim e ao cabo, distribuíam os produtos ao consumidor final. 
Não se pode apontar com precisão o que teria ocorrido se, no desenvolvimento do direito de autor, a atribuição de privilégios fosse outorgada aos distribuidores finais, ou seja, aos livreiros (o que historicamente poderia ser uma hipótese). Mas, ainda assim, cabe indicar que talvez a distinção entre o direito de propriedade ordinária e o conceito de propriedade intelectual sofressem, no futuro, interpretações diferentes das que lhes foram dadas naquela ocasião, mas essa ideia é mera especulação. Tudo isso, porém, não deixa de trazer curiosidade ao fato de um livreiro obter o privilégio de comercialização de produtos, mesmo que o privilégio fosse considerado, genericamente, um privilégio de impressão.

De alguma forma, portanto, ainda que indireta, cabe destacar que a tradição da impressão, nos seus primórdios, chegou à Portugal já em seus primeiros capítulos, assim como a muitos territórios europeus, como consequência da conhecida diáspora germânica ocorrida no século XV, após a invenção da imprensa.

Há porém, quem parece não concordar exatamente com essas ideias, argumentando que "estava já a tipografia acentuadamente desenvolvida quando fez a sua entrada na Hespanha, e o aspecto sumamente antiquado das primeiras produções aqui nascidas deve-se mais à imperícia dos executantes do que ao estado geral da nova arte gráfica” (Moniz, 1913, p. $3)^{8}$.

Também não há absoluta precisão quanto ao fato gerador da referida diáspora germânica, mas se pode apontar duas ideias básicas que a justificam e que influenciam, pois, o surgimento dos primeiros privilégios, tal como os de 1502 e 1503 atribuídos a Valentim Fernandes.

A primeira delas seria de que o mercado local não absorveria a quantidade de prensas originárias da região, argumento bastante razoável considerando que todo o advento criativo capitalista necessita de uma ampliação de mercado. Considerando que o restante da Europa necessitaria obviamente de uma circulação de bens produzidos por essa nova indústria, é razoável crer que a diáspora germânica decorreu da necessidade de ampliação do mercado, o que inclui, obviamente, a península ibérica, aqui amplamente nomeada. Há indicações, porém, de uma segunda justificativa,

8 Hespanha, na citação, remete ao território que hoje abarca a Península Ibérica, ou seja, Espanha e Portugal. 
bastante mais específica, que se refere ao fato de que a sucessão do Arcebispo de Mogúncia (Mainz) teria provocado a partida dos assessores de Gutemberg para fora da cidade. A data mais provável para a morte de Gutemberg é o ano de 1468, o que significa dizer que antes disso o êxodo de seus assessores já teria ocorrido. Independentemente da razão real para o êxodo, é inconteste que, para o idioma e para a cultura portuguesas, esse fator histórico foi suficiente para enquadrar Portugal como um país também pioneiro no desenvolvimento da tipografia e da imprensa, assim como ocorreu com outras nações europeias.

É importante também destacar que Valentim Fernandes iria acabar por ser reconhecido não somente pela sua importância como precursor na tipografia, como impressor e livreiro, mas, igualmente, pela sua atuação como coletor ${ }^{9}$ de fatos acerca dos descobrimentos e das viagens a esses relacionadas, o que, no contexto da história portuguesa, é um feito absolutamente relevante, especialmente pela importância crucial do pioneirismo português nas navegações e em todo o processo histórico dos descobrimentos. Ele seria, portanto, um entusiasta de aventuras e um contador de suas próprias histórias e de terceiros, o que se constitui como importante temática nos primórdios da imprensa, e também um importante gênero literário.

Além de sua relevância como impressor e entusiasta das impressões de obras de terceiros que contêm aventuras, Valentim Fernandes é historicamente reconhecido por ter escrito os Manuscritos de Valentim Fernandes, texto que se insere no rol dos relatos de viagens. Além desse texto, ele também é o responsável pela denominada Certidão de Valentim Fernandes ou Ato Notarial de Valentim Fernandes, que se constitui como um manuscrito (dentre outros poucos e raríssimos da época) escrito em latim, pelo próprio Valentim, para descrever a expedição datada de 1501/1502 em terras brasileiras, expedição da qual participou Américo Vespúcio. O referido documento é importante fonte que une a história de Portugal com a história do Brasil Colonial. O documento perdeu-se no tempo e, ao que parece segundo a doutrina e amplas pesquisas documentais

9 A utilização da expressão coletor de fatos é relevante (e comumente utilizada), considerando a distância entre a cotidianidade da vida dos centros urbanos de então e as viagens e os grandes descobrimentos da época. 
reiteradas, resta somente uma cópia dele ${ }^{10}$. Ainda que esses escritos não se configurem como textos especificamente relacionados à história do direito de autor, merecem destaque pela importância que tiveram na vida de Valentim.

Outra relevante e importante informação sobre a atuação de Valentim Fernandes como impressor e editor decorre do fato de que ele, em certa medida, deixou sucessores diretos em suas atividades, que eram então consideradas bastante nobres. Pode-se, pois, em alguma medida, atribuir a Germão Galharde (German Gaillard) a condição de sucessor direto de Valentim Fernandes, tendo em vista ter aquele adquirido dos seus herdeiros o material tipográfico do livreiro germânico, que acabou sendo utilizado pelo tipógrafo de origem francesa.

Por outro lado, com a análise específica do privilégio atribuído na data de 1503 (e seu antecessor em 1502), é curioso notar como a atribuição de privilégios se deu num intervalo de tempo relativamente curto em diferentes países da Europa, sendo certo que o mesmo não pode ser dito sobre o interstício temporal entre as leis europeias específicas sobre direito de autor.

Nesse sentido, a atribuição de um privilégio em Portugal, na ocasião indicada, e do privilégio anteriormente atribuído na Itália, em 1469, para Johannes de Speyes - somente para situar a diferença temporal numa comparação explícita - mostra que até aquele momento histórico as atribuições de privilégio possuíam uma relação estabelecida com o poder, especialmente as monarquias europeias, e possibilitavam elevado controle dos meios de informação.

Isso ocorria por uma razão evidente: a atribuição de privilégios mantinha a possibilidade de controle exatamente nas mãos daqueles que os atribuíam e garantia certa subordinação ou, no mínimo, garantia uma espécie de manutenção de poder. Não por acaso, a atribuição de privilégios se reveste de possibilidade de controle e de censura. Nesse sentido, deve-se recordar o fato de que o desenvolvimento econômico da imprensa introduz

10 Como indicam Amado e Figueiredo, o documento que se utiliza como fonte primária é um traslado, também em latim, que teria sido escrito e autenticado por Silvério Wyenhorst, tabelião, assim como Valentim, e que faz parte do que se denomina Códice Peutinger, por ter sido parte da coleção do Contado Peutinger, conselheiro do Imperador Maximiliano. O documento trasladado recebeu o nome Navegação dos portugueses para além do círculo equinocial (Amado; Figueiredo, 1997, p. 5). 
o debate no universo dos temas de relevo para a sociedade, o que inclui questões de ordem econômica, e não necessariamente o ponto de vista dos empresários do setor da impressão ou tipografia em controlar o conteúdo. O controle do conteúdo, obviamente, era interesse do Estado, mas o que particularmente interessava ao empresariado eram as garantias econômicas para o investimento, como já fartamente se tem conhecimento. Os privilégios correspondem, pois, a um dos elementos que possibilitam maior interesse no investimento e, evidentemente, tal circunstância decorre da exclusividade.

No caso do privilégio atribuído a Valentim Fernandes para os Regymentos dos Juizes e oficiaes, constata-se, a toda à evidência, que o pedido para a atribuição do privilégio foi requerido quando a obra objeto da exclusividade já estava impressa, como afirmado anteriormente. Os impressores/livreiros/editores, portanto, iriam compreender a necessidade de investimento para alcançar o seu interesse sendo, assim, relevante considerar, fundamentalmente, o caráter econômico das impressões, como bem indica a lição de Lucas e Lucas (2001, p. 4):

O aparecimento da impressão traz ao debate uma dimensão econômica que provoca a intervenção real (monárquica). Os impressores, igualmente denominados livreiros e quem, na acepção atual do termo são ao mesmo tempo também editores vão, em efeito, solicitar os privilégios para rentabilizar os investimentos importantes que implicam nos trabalhos de revisão de manuscritos e nas operações de fabricação (produção).

Ora, no caso de Valentim Fernandes e do privilégio em análise, parece ter havido uma garantia para a produção já efetuada, ou, dito de outra forma, para o investimento já promovido. Ao mesmo tempo, parece ser razoável que o Estado tenha algum controle sobre a empresa que irá providenciar os exemplares que contenham os Regymentos dos Juízes e oficiaes. Isso porque, quando se pensa em censura, pode-se contemplar o controle de conteúdo sob duas formas: 1 - ter antecipadamente conhecimento do conteúdo das obras a serem editadas e impressas e; 2 ter certeza de que as obras que se tem interesse em editar e imprimir não irão ostentar outro conteúdo.

Para o eficaz controle, é fundamental que o Estado possa, no mínimo, acompanhar de perto as edições. No caso do privilégio de 1503, o Estado controlou completamente o seu conteúdo e o determinou ao impressor. E, 
ademais, o conteúdo era já também controlado antes mesmo da vinculação ao privilégio que autorizaria a sua impressão, por ser conteúdo definido pelo próprio Estado, pois se tratava do Regymento para Juízes e Oficiais.

Há aqueles, portanto, que compreendem que o desenvolvimento da imprensa seria lento em decorrência da necessidade de manutenção do poder nas mãos do status quo, como é o caso de Sodré: "Como as trocas interessavam apenas a elementos de classes e camadas numericamente reduzidas entretanto o desenvolvimento da imprensa foi muito lento naquela fase, e ela foi facilmente controlada pela autoridade governamental" (Sodré, 1966, p.02).

Como se pode concluir, o privilégio atribuído a Valentim Fernandes em 1503 traz relevantes temas de discussão nos primeiros momentos da biografia do direito de autor, especialmente no que se refere às relações de poder.

\section{CARTA ATRIBUINDO A JACOBO CROMBERGER AS MESMAS GRAÇAS, PRIVILÉGIOS, LIBERDADES E HONRAS ATRIBUÍDAS AOS CAVALEIROS DA CASA REAL PORTUGUESA}

Jacobo Cromberger foi outro impressor alemão que, além de Valentim Fernandes e outros pioneiros da tipografia, atuou em Portugal, tendo ali também chegado como consequência da diáspora germânica.

É um sobrenome que historicamente se destaca nos primórdios da história da imprensa e do direito de autor, pois acabou formando uma família de impressores e livreiros na península ibérica. Jacobo Cromberger estabeleceu-se em Sevilha e aí desenvolveu a sua imprensa, tendo sido beneficiário de privilégios importantes, como o privilégio das mercês, que são o objeto destas breves linhas.

Cromberger trabalhou com destacados impressores espanhóis como, por exemplo, Estanislao Polo - e um curioso episódio de sua vida particular que trouxe reflexos para a vida profissional foi o fato de que ele se casou com a viúva de Polo e acabou por controlar a imprensa que havia sido de propriedade deste.

Por outro lado, Jacobo é bem mais referido por suas impressões na Espanha do que em Portugal, uma vez que sua carreira naquele país foi 
bastante longeva e, segundo consta, foi na Espanha, especialmente em Sevilha, que sua produção teve maior destaque.

Posteriormente, a família Cromberger seguiu o ofício de seu patriarca, tendo sido seu filho, Juan Cromberger, o fundador da imprensa na América (no México) e seu neto, que recebeu o nome do avô, sucedeu-os no mesmo ofício.

No início de suas atividades, Jacobo chegou a editar cerca de 600 títulos, número bastante expressivo para a época. Tais dados servem como uma espécie de certificação para ilustrar e mostrar a magnitude das impressões de Cromberger. Como medida de comparação, para se alcançar a dimensão do número de obras editadas e de exemplares circulantes, vale referir as informações coletadas por Katzenstein, entre outros autores, que indicam o quanto a difusão dos livros era resumida antes do advento da impressão pelos tipos móveis. A autora apresenta os números de exemplares em diversas bibliotecas, e as quantidades são absurdamente baixas: a biblioteca do imperador Carlos V da França, em 1364, consistia em 900 exemplares; a biblioteca da Catedral de Estrasburgo, em 91 manuscritos; a do Louvre, considerada o "Paraíso dos Livros", em 1000 exemplares, por exemplo. No mais, revela a autora que um doutor em Direito possuiria no máximo seis livros e que um Doutor em Medicina, até cinco (Katzenstein, 1986, p. 343).

Por outro lado, é importante também salientar que Cromberger já tinha carreira no território espanhol antes de atuar em terras portuguesas, sendo bastante prestigiado naquele país, e que ingressou em terras lusitanas a convite do Rei Manuel I que, ao conhecer a fama de Jacobo, o convidou para exercer seu ofício em Portugal. Foi para esse mesmo monarca que ele editou as relevantes Ordenações Manuelinas, em 1521, ainda que essa não seja uma informação unânime entre os historiadores, não sendo, por exemplo, o entendimento de Norton:

Em 1521, surgiu uma coleção de ordenanças reais portuguesas em cinco partes, cada uma assinada por Cromberger, duas delas com a impressão em Évora e três, incluindo a última e única datada de 11 de março, como de Lisboa. As circunstâncias são um pouco misteriosas, pois há provas documentais da presença de Cromberger em Sevilha até 26 de janeiro, e o volume era um folio de mais de 500 folhas cuja impressão pode ter custado pouco tempo. Não são conhecidas outras impressões 
portuguesas, pensou que foi durante uma visita a Lisboa que morreu em 1528 (Norton, 1966, p. 13).

Cromberger foi convidado a exercer o oficio de impressor em território português, como dito, pelo próprio monarca. Mas o documento contendo a autorização e o privilégio para impressão era muito mais amplo, dando-lhe a condição de exercer seus ofícios e viver sua vida como um membro da casa real. Ou seja, mais do que a exclusividade para imprimir ou vender livros, Cromberger recebe a outorga para beneficiar-se de todas as condições inerentes aos membros da casa real portuguesa. Não se trata, portanto, de um simples privilégio de impressão.

Por outro lado, também há de se analisar não somente o conteúdo do documento, ou seja, o fato de que ele prevê privilégios, garantias e, obviamente, a natureza de tais condições, mas também a natureza do documento em si. Sua compreensão é relevante para avaliar a importância e o sentido histórico das atribuições de privilégio com a finalidade de construção de uma biografia do direito de autor.

O documento que se analisa não é um alvará ou um privilégio, mas, em verdade, uma carta indicando todas as vantagens, privilégios e condições que foram atribuídas pelo monarca ao seu beneficiário, Jacobo Cromberger, até mesmo porque é assim que o documento se auto-refere e como começa a indicar a sua definição, já nas primeiras linhas: “Dom Manuell etc. Aquamtos esta nossa carta_virem fazemos saber que, avendo nos Respeyto ao que em sua petiçam diz yacobo cromberger" (Portugal, 1508, p.01).

A expressão carta consta mais duas vezes, ao longo do documento, enquanto a expressão privilégio aparece três vezes, já a expressão alvará não é empregada em momento algum.

Deslandes, por sua vez, entende que o documento deveria ser considerado um alvará, não obstante essa expressão não figurar nele. Ainda assim, esse autor irá referir, em sua obra de 1881, que:

Jacob Cromberger era allemão e impressor de livros. Foi convidado a servir em Portugal, onde requereu e alcançou a 20 de fevereiro do anno de 1508 a mercê de todas as graças, privilegios, liberdades e honras que então haviam os cavalleiros da real casa. O alvará da mercê concede a mesma distincção a todos quantos então exerciam ou de futuro viessem a exercer nobre arte da typographia (1881, p. 7, grifamos) 
Deve-se salientar que não há, entre o uso das expressões carta ou alvará, polêmica que interfira, nesse caso, na natureza jurídica do documento ou mesmo nos direitos que dele emanavam. Isso porque alvará, ao fim e ao cabo, é documento que autoriza ou ordena determinados fatos e que possui valor jurídico. A diferença seria que o alvará atribui condições a determinadas pessoas e a obediência de seus termos a terceiros. Já a carta seria um documento mais genérico, que simplesmente anunciaria determinada condição, e este parece ser exatamente o caso do documento ora comentado. Discussões referentes à natureza jurídica à parte, o que realmente se coloca como relevante em relação ao documento em apreço são outras questões, como, por exemplo, o seu caráter de privilégio, até porque essa é a expressão que emana dos primeiros documentos que autorizavam as impressões das primeiras obras publicadas num ambiente de análise do direito de autor e do direito da literatura. Releva, pois, muito mais do que analisar a natureza jurídica em si do documento, compreender se os privilégios são condições antecedentes dos direitos, visto que estes são genéricos, enquanto aqueles são específicos. No mais, importa também compreender a natureza dos privilégios atribuídos, mais do que a dos documentos em si mesmos.

A utilização da expressão privilégios, no documento analisado, deu-se em conjunto com outras, quais sejam: graças, liberdades e honras. Todas elas são condições que eram aplicadas aos cavaleiros da casa real portuguesa. Ou seja, a carta que ora se analisa atribuiu ao impressor Jacobo Cromberger muito mais do que somente a autorização para imprimir obras ou simplesmente livros, mas também outras condições valiosas que ele recebeu por algumas razões, todas relacionadas entre si: por já ser renomado impressor no território espanhol, por ser figura considerada de relevo social naquele país e por ter sido convidado diretamente por Dom Manuel I para atuar no território português.

Assim, Jacobo recebeu mais do que uma simples condecoração e permissão para impressão, mas todas as honras aplicáveis aos cavaleiros da real casa portuguesa. Ingressou no território português, por assim dizer, pela porta principal. 
E, repare-se, em nenhum momento se delimita qualquer atuação por parte do impressor alemão, nem se atribui limites ao que ele poderia imprimir ou como poderia atuar no então incipiente mercado da indústria da impressão.

Muito pelo contrário, a interpretação do texto da carta permite que muito se possa atribuir ao seu beneficiário, como se percebe, por exemplo, neste pequeno trecho:

E mandamos a todollos oficiaes e pesoas dos ditos nosos Regnos e senhorios a que esta nosa carta for mostrada e o conhecimento della pertencer que aos ditos ymprimidores, que o dito cabedall e as mais cousas teverem e dellas uzarem em proll destes nosos Regnos e senhorios, guardem o dito privillegio homras e liberdades asy e tam compridamente como em esta nosa carta he conteudo sem duvida nem embargo allgum que a ello lhe seya posto, porque asy he nosa mercê (Portugal, 1508, p. 1).

Não parece haver dúvidas, portanto, que a condição que Cromberger ostentava era altamente privilegiada, o que era passível de conduzir a determinados conflitos com os seus colegas de ofício, ainda que não se tenha notícia de tais fatos. Por outro lado, pode-se obviamente concluir que a relação com o rei Dom Manuel I iria permitir o controle das obras que fossem publicadas e uma relação altamente promíscua entre o poder do Estado e a posição ostentada por Jacobo.

Crombeger, portanto, se comparado com Valentim Fernandes e considerando ambos os pioneiros dentre os pioneiros de um direito de autor embrionário e do direito da literatura, possuía privilégios mais amplos do que este, pelo menos no que se refere ao alcance genérico das benesses que lhe vieram a ser outorgadas.

De toda forma, se Jacobo Cromberger chegou a usufruir plenamente dos benefícios alcançados com o conteúdo e as atribuições decorrentes dessa carta é algo que a biografia do direito de autor não pode apontar com absoluta segurança até o momento.

\section{CONCLUSÃO}

Como previamente indicado, este estudo teve como objeto de análise os três primeiros privilégios atribuídos no universo dos países de língua portuguesa e que não se constituíam, ainda, como privilégios autorais. Esse 
processo histórico corresponde aos primeiros passos da biografia do direito de autor e do direito da literatura nos países de língua portuguesa, assim como no ambiente peninsular e, até mesmo, no contexto europeu em geral.

Como consequência, o estudo buscou favorecer a compreensão dos diversos sentidos atribuídos à expressão privilégios, com o objetivo de avaliar se a interpretação adotada pela doutrina autoralista está de acordo com as várias acepções apresentadas por este artigo. Por outro lado, também apresenta análises sobre os privilégios pioneiros e suas relações com impressores e sujeitos-criadores.

Também do ponto de vista terminológico, o estudo apresentou as diferenças na compreensão de expressões associadas aos privilégios - como carta e alvará - para que se pudesse elucidar as diferentes acepções da expressão privilégios, concluindo que, com mais razão, essa não poderia ser, exatamente, sinônimo de carta, carta régia ou alvará. Por outro lado, também foram apresentadas as semelhanças e diferenças nas atribuições dos privilégios aos pioneiros do direito de autor e, mais especificamente, de um direito da literatura em Portugal: Valentim Fernandes e Jacobo Cromberger. A ambos pode-se atribuir a condição de beneficiários de privilégios de impressão atentando-se às particularidades que importam a cada um deles.

Como conclusão geral, pode-se afirmar que os privilégios de impressão, ainda que possam ser considerados os antecedentes das leis nacionais de direito de autor, não representavam, no mais recôndito início da biografia do direito de autor, a atribuição de outorgas de poderes aos sujeitos-criadores. No particular caso de Portugal, somente no ano de 1536 haveria de se atribuir um privilégio especificamente a um sujeito-criador, que, nesse caso foi Gonçalo de Baena, seguido, no ano subsequente, de Balthasar Dias.

Por fim, no que se refere à atribuição de direitos (e não mais de privilégios), em países como Portugal e Brasil, ela decorrerá do alcance de determinados elementos relacionados à revolução francesa e, nesse particular, obviamente que os resultados alcançados irão impactar os países que receberam influência direta dos movimentos políticos revolucionários, o que inclui o surgimento do direito de autor em idioma português, especialmente no que respeita às suas constituições de caráter liberal. 
Ocorre que, até se chegar aos movimentos revolucionários e liberais, o desenvolvimento histórico dos privilégios foi fundamental na sedimentação de ideias sobre a proteção da criação artística, intelectual e literária. Por outro lado, é importante compreender, ainda, que as primeiras leis de países como Portugal acabam por ser bastante posteriores, se comparadas com as primeiras leis da Inglaterra e França, países pioneiros na atribuição de legislações autorais. Essa evolução, como se pode concluir, faz parte de um momento histórico bastante posterior e, mesmo que mereça indicação, será melhor compreendida por estudo particularmente voltado à análise dos movimentos históricos dos séculos XVIII e XIX.

Se é verdade, pois, que o direito da literatura em língua portuguesa terá início no século XVI, com a atribuição de privilégios, e sendo certo que o autor (sujeito-criador) não está incluído entre os seus primeiros privilegiados, tal circunstância também aponta para a possível incompreensão, à época, da figura do autor.

Todo esse entorno histórico ajuda a explicar porque o direto de autor, atualmente, ainda - ou cada vez mais - acaba sendo considerado um direito inerente ao investimento, muito mais do que protetivo do processo criativo em si mesmo, fato que compreendo ser um equívoco da ordem estrutural e um efetivo desentendimento da função do direito.

\section{REFERÊNCIAS}

AMADO, Janaina; FIGUEIREDO, Luiz Carlos. A Certidão de Valentim Fernandes, documento pouco conhecido sobre o Brasil de 1500. Textos de História, v. 5, n. 2, p. 133-142, 1997. Disponível em: <http://periodicos.unb.br/index.php/textos/article/view/5872/4853>. Acesso em: 10 jan. 2017.

DESLANDES, Venâncio Augusto. Documentos para a história da typographia portuguesa nos séculos XVI e XVII. Lisboa: Imprensa Nacional, 1881. Disponível em: $<$ https://ia800203.us.archive.org/12/items/documentosparaa12portgoog/ documentosparaa12portgoog.pdf $>$. Acesso em: 02 mar. 2017.

DIAS, João José Alves. Os primeiros impressores alemães em Portugal. In: DIAS, João José Alves (Coord.). O quinto centenário da "Vita Christi". Lisboa: Instituto da Biblioteca Nacional e do Livro, 1995. p. 15-27.

ESCUDERO, José António. Curso de Historia del Derecho; fuentes e instituciones político-administrativas. Madrid: Edisofer. 2012.

GILISSEN, John. Introdução histórica ao direito. 7. ed. Lisboa: Calouste Gulbenkian. 2013. 
HESPANHA, António Manuel. Cultura jurídica européia; síntese de um milênio. Coimbra: Almedina, 2012.

GARCIA-GALLO, Alfonso. Manuel de história del derecho espanhol, metodologia histórico jurídica, antologia de fuentes del derecho español; volumen II. Madrid: [s. ed.], 1971.

KATZENSTEIN, Úrsula E. A origem do livro: da idade da pedra ao advento da impressão tipográfica no ocidente. São Paulo: Hucitec; Instituto Nacional do Livro, 1986.

LEITÃO, Luiz Manuel Teles de Menezes. Direito de autor. Coimbra: Almedina. 2011.

LUCAS, André; LUCAS, Henri-Jacques. Droit d'auteur et droits voisins. 2. ed. Paris: Litec, 2001.

MONIZ, José A. Lições de Bibliologia; a imprensa em Hespanha no século XV (notas subsidiárias). Lisboa: Guimarães, 1913.

NORTON, F. J., Printing in Spain, 1501-1520. Cambridge: Cambridge University Press, 1966.

PEREIRA, Alexandre Libório Dias. Direitos de autor e liberdade de informação. Coimbra: Almedina, 2008.

PORTUGAL. Privilégio impresso no livro com as histórias de viagem de Marco Paulo impresso por Valentim Fernandes, com indicação do privilégio real que lhe foi atribuído em sua capa para a impressão exclusiva da referida obra no ano de 1502. Privilégio atribuído por Dom Manuel I. Biblioteca Nacional de Portugal, biblioteca digital (http://www.bnportugal.pt/), catálogo das obras publicadas no ano de 1502.

PORTUGAL. Carta atribuindo a Jacob Cromberger as mesmas graças, privilégios, liberdades e honras atribuídas aos cavaleiros da casa real portuguesa Privilégio atribuído por Dom Manuel I. 1503. Exemplar microfilmado e arquivado no Arquivo Nacional da Torre do Tombo, com a cota: Chancelaria de Dom Manuel, livro V, fol. 6 v.

ROGEL VIDE, Carlos; DRUMMOND, Victor. Manual de direito autoral. 2. ed. Rio de Janeiro: Lumen Juris, 2010.

Idioma original: Português

Recebido: 20/04/17

Aceito: 04/05/17 